\title{
Comportamiento reológico de geles biodegradables para aplicaciones en medicina regenerativa
}

\author{
F. REYES ORTEGA ${ }^{1}$, G. RODRÍGUEZ ${ }^{1}$, M. ROSA AGUILAR ${ }^{1}$, \\ J. GARCÍA-SANMARTÍN ${ }^{2}$, A. MARTÍNEZ ${ }^{2}$, J. SAN ROMÁN ${ }^{1}$ \\ ${ }^{1}$ Instituto de Ciencia y Tecnología de Polímeros. CSIC. \\ ${ }^{2}$ Centro de Investigación Biomédica de La Rioja.
}

\begin{abstract}
Resumen
Los hidrogeles $(H G)$ poliméricos son redes macromoleculares tridimensionales constituidas por elementos básicos conectados entre sífísica o químicamente e hinchados por un disolvente. Los $H G$ poliméricos tienen múltiples aplicaciones, entre ellas su utilización en el desarrollo de materiales para regeneración de tejidos gracias a su alta biocompatibilidad y su uso frecuentemente como sistemas de liberación de fármacos debido a su capacidad para retener líquidos y compuestos bioactivos. En este trabajo se han preparado HG poliméricos formados por dos componentes altamente biocompatibles como son la gelatina y el ácido hialurónico, estabilizados con distintas concentraciones de genipina, consiguiendo diferentes grados de entrecruzamiento. Para comprobar la resistencia mecanodinámica y la estabilidad de estos hidrogeles, se realizaron ensayos termogravimétricos, estudios reológicos y estudios de hinchamiento de los mismos utilizando distintos medios tamponados. El uso de estos HG como sistema portador de fármacos se ha ensayado en un modelo experimental in vivo de ratón, utilizando el péptido $N$-terminal de 20 aminoácidos de la proadrenomedulina (PAMP) que posee propiedades angiogénicas, re-epitalizantes y antimicrobianas.
\end{abstract}

\begin{abstract}
Hydrogels $(H G)$ are polymeric three-dimensional macromolecular networks formed by basic elements physically or chemically interconnected and swollen by a solvent. Polymeric HG have multiple applications, including their use in developing materials for tissue regeneration due to their excellent biocompatibility and their frequent use as drug delivery systems because of their ability to hold liquids and bioactive compounds. In this work, polymeric HG have been prepared with two highly biocompatible components such as gelatin and hyaluronic acid, stabilized with different concentrations of genipin, achieving different degrees of crosslinking. The mechanodynamic resistance and the stability of these hydrogels were tested with thermogravimetric assays, rheological tests and swelling measurements using various buffered media. The use of these HG as a drug carrier system has been tested in an experimental in vivo mouse model, using the 20 aminoacid $N$-terminal peptide of proadrenomedullin (PAMP) with angiogenic, antimicrobial and re-epithelizing properties.
\end{abstract}

Correspondencia:

Felisa Reyes Ortega

Instituto de Ciencia y Tecnlogía de Polímeros. CSIC

C/ Juan de la Cierva 3. 28006 Madrid

felireyes@ictp.csic.es 


\section{Introducción}

La descripción de nuevos biomateriales y sistemas utilizados en medicina regenerativa, que sean fisiológicamente eficaces y mecánicamente funcionales, se ha desarrollado en las últimas décadas de forma vertiginosa, en aplicaciones como injertos vasculares, portadores para liberació controlada de f́r estos biomateriales requiere la investigación y ecterizacion the de su estuctura como de sas propiedades mećn sus defiendo pún que perdich que permitan evaluar las interacciones entre un biomaterial con un sistema biológico y analizando su comportamiento tras la implantación'. Los requisitos que debe cumplir un biomaterial para poder ser utilizado en medicina regenerativa son: 1) ser biocompatible, aceptado por el organismo receptor, 2) ser químicamente estable y biodegradable, al menos durante el tiempo programado para , as 3) tener la mecánicas y peso molecular adecuados, 4) presentar un y pecu diseño, tamañ y forma er impla 5 , terse e eproducible, facil procesamiento para su

Los hidrogeles (HG) son materiales poliméricos entrecruzados, de origen natural o sintético, en forma de red tridimensional que cuando entran en contacto con el agua se hinchan y forman compuestos elásticos, blandos, flexibles y que además retienen una centidad significativa de esa mismás . ${ }^{2}$ Los HG polisma estructura, pero sin disolic 2 Los HO polimericos tienen múltiples aplicaciones en el campo de los biomateriales, entre ellas su utilización en el desarrollo de materiales para regeneración de tejidos gracias a su alta biocompatibilidad y su uso frecuentemente como sistemas de liberación de medicamentos debido a su capacidad para retener una amplia gama de compuestos bioactivos. ${ }^{3,4} \mathrm{La}$ flexibilidad en las cadenas que poseen los sólidos poliméricos los convierte en aptos para formar geles, ya que permite que difundan moléculas de disolvente pu interior, forne ger tridien ficar tidion ficar en varios tipos, siempre teniendo en cuenta a naturaleza de las uniones que posee la red que los constituye. Los geles físicos, son aquellos que poseen una red tridimensional formada por uniones iónicas o de tipo Van der Waals, dando lugar a redes reversibles, ${ }^{5}$ es decir, una vez formados (transcurrida la transición sol-gel) pueden sufrir la transición inversa ( $\mathrm{gel}$-sol) sin degradarse. Por su parte, reciben la denominación de geles químicos, aquellos en los que la red está formada por enlaces covalentes, originándose una red irreversible, en a que es necesario su degradación para volver a estado sol inicial.

Los HG que presentan ambos tipos de entrecruzamiento, físico y químico, dan lugar a redes semi-interpenetradas (SINP). Este tipo de redes poseen la capacidad de sufrir deformaciones tem-

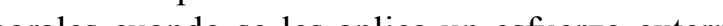
limita Dicha deformación desaparece cuando el esfuerzo cesa, y el HG parcialmente su estructura inicial, mientas que tra parte esfuerzo aplicado se disipa en forma de calor. A este comportamiento se le denomin viscoelástico y es característico de los polímeros. El estudio de estas propiedades viscoelásticas se puede llevar a cabo por reología, a partir de ensayos dinámicos de esfuerzo-deformación. ${ }^{6}$

Los componentes elegidos en este trabajo para llevar a cabo la preparación de estas redes semihan sido el ácido hialurónico y 1 gelatina, componentes biodegradables y bioconpatibles de orgen entorno similar a la matriz extractar y ade pesno similar a la matriz extracelular y adema presentan propiedades adecuadas (flexibilidad, hidrofilia, etc.) para su utilización en regeneración de tejidos (figura 1).

El ácido hialurónico (AH), un glucosaminoglicano no sulfatado de alto peso molecular que contiene grupos funcionales de ácido carboxílico, es uno de los componentes principales de la matriz vial, el humor vítreo y la piel, y tejidos. También yumple un paplantinganos rio mediante la inhibición de la dest favorios verion. El AH tiene propiedades higroscópicas y viscoelásticas unicas. Cuando el AH se incorpora en un medio acuoso, se producen puentes de hidrógeno entre los grupos carboxilo y $\mathrm{N}$-acetil adyacentes, lo cual le permite mantener la rigidez y retener agua. ${ }^{8} \mathrm{Po}$ sus propiedades viscoelásticas puede ralentizar la penetración de los virus y bacterias, algo que reviste especial interés en la regeneración tisular, por ejemplo en el tratamiento de las enfermedades periodontales. ${ }^{9}$ Tiene múltiples funciones estructurales y fisiológicas en los tejidos, como las interacciones celulares, interacciones con los factore de crecimiento, regulación de la presión osmótic y la lubricación tisular, lo cual contribuye a mantener la integridad homeostática y estructural de los tejidos. ${ }^{10}$

La gelatina es una proteína compleja que se obtiene a partir de la degradación térmica o enzimática del colágeno. En su estructura química apare- cen residuos de lisina o glutamina que presentan grupos amino libre que pueden actuar como puntos de entrecruzamiento y asi obtener un gel mucho más estable. La gelatina es un biopolímero biodegradable con una excelente bioafinidad, por lo que se utiliza muy activamente en aplicaciones farmacéuticas y oftalmólogas. ${ }^{11} \mathrm{Sin}$ embargo la gelatin ce disur y ón cedos, 10 que limita sus aplicaciones bionedicas. El entrecruzamiento fisico o quimico de la gelatina mejor la estabilidad del material frente a degradaciones enzimáticas que se pueden dar en el organismo. El entrecruzamiento físico que se puede producir por radiación UV o deshidratación presenta el inconveniente de que es dificil controlar la densidad de entrecruzamiento de la matriz polimérica. ${ }^{13} \mathrm{En}$ cambio, con un entrecruzamiento químico podemos controlar fácil y eficazmente la densidad de entrecruzamiento de la red tridimensionalen funcre le la cor cion de la corcentacion de agen a en obteniendo una matiz formada a partir de enlaces covalentes que proporciona una mayor estabilidad mecánica.6 El entrecruzante químico convencional utilizado para entrecruzar matrices de gelatin
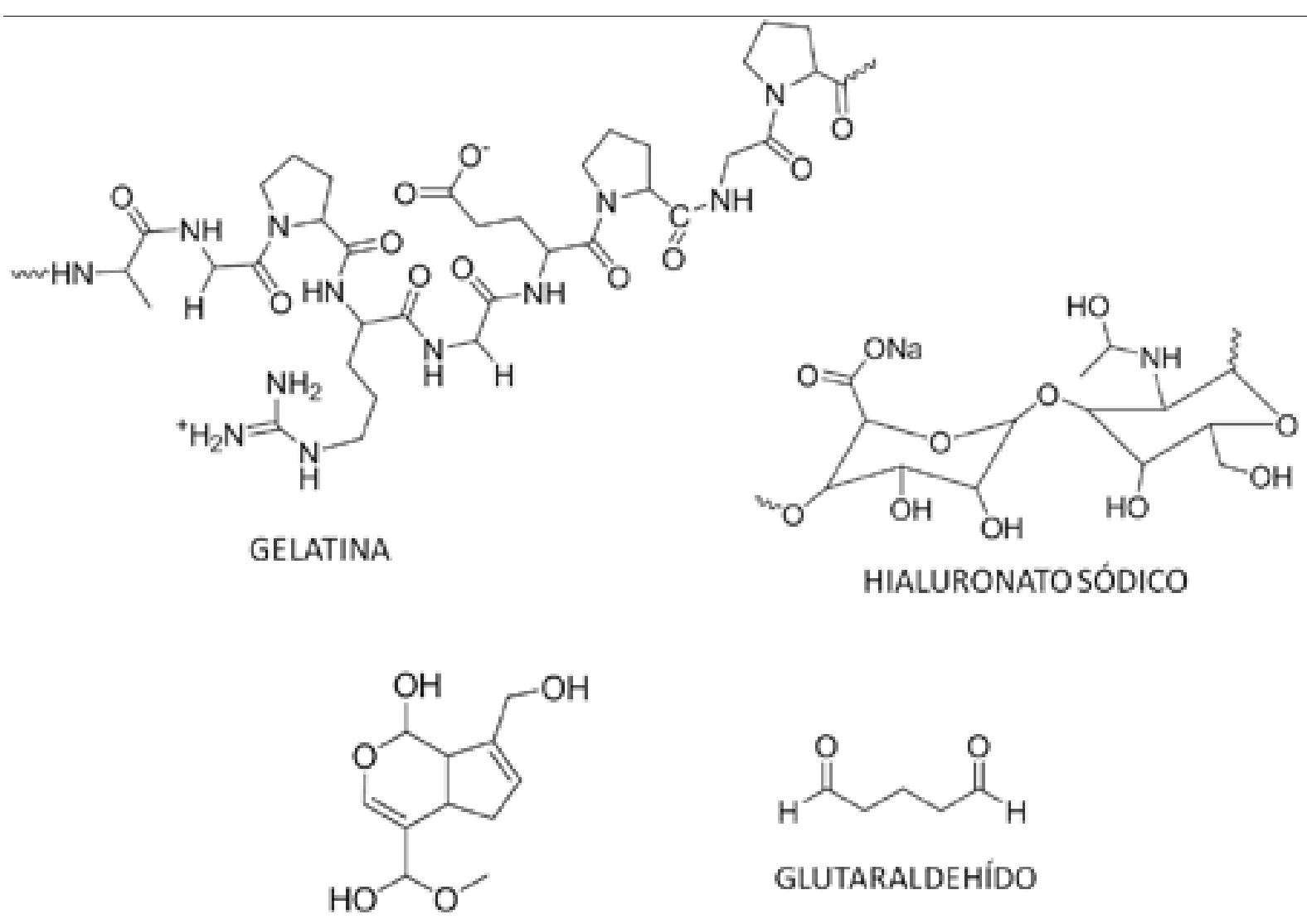

GENIPINA

Figura 1. Esquema de las estructuras químicas de la gelatina, el hialuronato sódico, la genipina y el glutaraldehído.
HIALURONATOSÓDICO

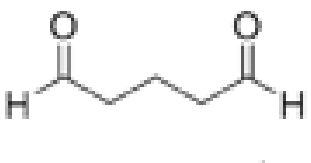

ha sido el glutaraldehído (GTA) (figura 1), ${ }^{14,15} \mathrm{sin}$ coxicidad y los posterio presenta. 16,17
ción a flor de jazmín que desde hace tiempo se usa en a medicina tradicional china para tratar la diabetes (figura 1). Este reactivo surge como una alternativa a los agentes entrecruzantes convencionaes empleados para la gelatina, debido a su buen En zalimericos estabilizados con Ela entrecruzamiento. mente biocompatibles or dos componentes altahialuronato sódico, han sido cargados con una moécula biológicamente activa, como es el péptido $N$-terminal de 20 aminoácidos de la proadrenomedulina (PAMP) que posee propiedades angiogénicas, re-epitalizantes y antimicrobianas ${ }^{21,22}$ con el fin de estudiar y desarrollar un sistema portado de fármacos para su aplicación en regeneración de tejidos.

\section{GLUTARALDEHIDO} embargo, estudios previos han demostrado su alta

La genipina es un producto natural extraído de 
Materiales

La gelatina (GE) de cerdo tipo A de 300 bloom Ensayos in vivo del HG cargado con PAMP: mose obtuvo de Sigma-Aldrich, el hialuronato sódico (HA) grado oral de peso molecular $100 \mathrm{kD}$ se obtuvo de Bioibérica, la genipina se obtuvo de Challenge Bioproducts Co. Estos reactivos se uti-

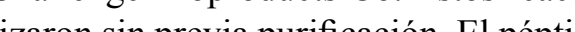
lizaron sin previa purificación. El péptido $N$-terminal de 20 aninacidos de la proadrenomedulin (PAMP) se adquirió de Phoenix Pharmaceutical $(\mathrm{Mw}=2460.87)$ y para su utilización se disolvió en una solución tampón fosfatado (PBS) $\mathrm{pH}=7.4$. E tampón fosfato (PBS) a pH=7.4 $(140 \mathrm{mM} \mathrm{NaCl}$, $10 \mathrm{mM}$ tampón fosfato, $3 \mathrm{mM} \mathrm{KCl}$ ), el tampón a $\mathrm{pH}=2$ (citrato / ácido clorhídrico) y el tampón a $\mathrm{pH}=10$ (ácido bórico / cloruro potásico / hidróxido sódico) se obtuvieron en Merck-Millipore en forma de polvo y se disolvieron en $1 \mathrm{~L}, 0.5 \mathrm{~L}$ y 0.5 Métodos

La preparación de los hidrogeles de gelatina ialuronato sódico se llevó a cabo por el método de casting o evaporación del disolvente. Para ello se preparó una mezcla directa a partir de las disoluciones acuosas de ambos componentes: $6 \mathrm{~mL}$ de una disolución acuosa de gelatina $(100 \mathrm{mg} / \mathrm{ml})$ y $8 \mathrm{~mL}$ de una disolución acuosa de hialuronato sódico $(50 \mathrm{mg} / \mathrm{ml})$. A dicha mezcla polimérica an ina $(0.5,1,2$ y $5 \%$ en peso respecto a pina $(0.5,1,2$ y $5 \%$ en peso respecto a la mezcla polimerica) para obtener distintos grados de entrecruzamiento del hidrogel. La mezcla con todos lo componentes se agitó a $200 \mathrm{rpm}$ durante $10 \mathrm{~min}$ se le aplicó ultrasonidos durante 5 min y rápidamente se depositó en un molde de teflón donde se dejo evaporar el agua a temperatura ambiente. El hidrogel seco se lavó con agua destilada varias veces (3-5) durante $2 \mathrm{~h}$, cambiando el agua cada 20 minutos para eliminar culquier resto de genipina que hubiera quedado sin entrecruzar. Finenipin los hidrogeles se secaron a tempera y se toqueloron para obener discos de 1 ciente y se troquelaron para obtener discos de $1 \mathrm{~cm}$ de

La incorporación del PAMP dentro del hidrogel se llevó a cabo depositando sobre el xerogel (hidrogel seco completamente) de $1 \mathrm{~cm}$ de diámetro, entrecruzado con un $1 \%$ de genipina, una disolución de PAMP $(0.5 \mathrm{ml}, 2 \mathrm{mM})$ y manteniendo durante $24 \mathrm{~h}$ el sistema en atmósfera saturada de agua para favorecer la difusión del PAMP en el HG. Tras 24h, el hidrogel se dejó secar a temperatura ambiente. Se prepararon 2 tipos de m muestra control (HG sin PAMP) y muestra cargada (HG cargado con $1 \mathrm{nmol}$ de PAMP).

Los ensayos in vivo se llevaron a cabo en el les. Se pilizo la linea de Fron C57BL/6 OTO, Se Ét siguiendo el ensayo aprobado por el Comté Ético de Experimentación Animal del CIBIR (CEEA-CIBIR) 01-09. Las dos muestras de hidrogeles (muestra cargada con $1 \mathrm{nmol}$ de PAMP muestra control que no contiene PAMP) preparadas fueron colocadas en un bolsillo practicado en la dermis dorsal de dichos ratones modificados genéticamente que expresan la proteína verde fluorescente (GFP) en los vasos sanguíneos. Despues de 5 dias, las membranas fueron extraídas y fijadas en formalina tamponada.

Para realizar el bolsillo en la dermis dorsal, los ratones recibieron anestesia inhalatoria con isofluorano. El dorso de los animales fue afeitado a cual y con la ayuda de tijeras de punta roma, se practicó un bolsillo en la dermis capaz de albergar el disco de hidrogel. El HG se hidrató con PBS se insertó en el bolsillo con la capa que contiene e PAMP dirigida hacia el animal. Una vez insertado lisco, se cerró la incisión con hilo de sutura y los aimase se devolvieron a jus jaulas. Después ex jeron los discos. Éstos fueron fijados en formo confocal.

Algunos HG fueron incluidos en parafina, cortados de manera transversal a la superficie del disco, y teñidos con hematoxilina-eosina para obtener la imagen histológica del corte.

\section{Caracterización}

La caracterización por ATR-FTIR se llevó a cabo colocando el hidrogel seco entre dos cristales de CaF2 de $2 \mathrm{~mm}$ de espesor y $25 \mathrm{~mm}$ de diámetro. Se utilizó un equipo Perkin-Elmer Spectrum One, realizando un barrido de 4000 a $600 \mathrm{~cm}^{-1}$ Se realizaron 32 barridos con una resolución de $4 \mathrm{~cm}^{-1}$

Para la determinación del grado de hinchamiento en distintos medios tamponados $(\mathrm{pH}=2$, 7.4 y 10), se pesaron los discos del hidrogel entrecruzado (10-30 mg) y se sumergieron en recipientes con $10 \mathrm{~mL}$ del tampón correspondiente y delo animal de ratón Centro de Investigación Biomédica de la Rioja se hizo una pequeña incisión en la piel, a través de se volvieron a anestesiar los ratones y se extratamponado al $10 \%$ y observados al microscopio se pusieron en un baño termostático a $37^{\circ} \mathrm{C}$. El hinchamiento se siguió gravimétricamente, midiendo la ganancia de agua con el tiempo de inmersión. A un tiempo determinado, se saca el disco, se seca cuidadosamente su superficie con un papel de filtro, se pesa y se devuelve al recipiente. Las medidas se hicieron por triplicado, tomando valor promedio con su corespoliente desvia var (SD) paracion estándar (SD) para el cálculo del porcentaje de
grado de hinchamiento a partir de la ecuación:

$\% \mathrm{H}=[(\mathrm{Wt}-\mathrm{W} 0) / \mathrm{W} 0] \cdot 100$

Donde $\mathrm{H}$ es el grado de hinchamiento (gramos de agua/gramo de hidrogel), $\mathrm{W}_{\mathrm{t}}$ es el peso del disco hinchado en el tiempo $t$ y $\mathrm{W}_{0}$ es el peso de disco seco.

El análisis termogravimétrico (TGA) se realizó en un equipo TGA Q500 (TA) entre $25 \mathrm{y} 600^{\circ} \mathrm{C}$ en atmósfera de nitrógeno a $10^{\circ} \mathrm{C} / \mathrm{min}$.

Las medidas de reología se llevaron a cabo en un reómetro oscilatorio de esfuerzo controlado de TA Instruments modelo ARG2, utilizando una geometría de platos paralelos. Las muestras en disolución se midieron utilizando un plato superior de polimetacrilato de metilo de $40 \mathrm{~mm}$ de diámetro. Para las muestras en estado gel se usó un plato superior de acero de $20 \mathrm{~mm}$ de diámetro. Se realizaron ensayos dinamomecánicos, fijando el porcentaje de deformación en un $2 \%$ y manteniendo la fuerza normal inicial constante para todas

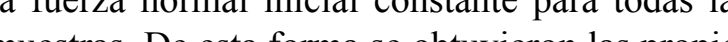
ades viscoelásticas de los hidrogeles, definidas partir de su módulo de almacenamiento (G') y su módulo de pérdidas (G”)

\section{Resultados y discusión}

El entrecruzamiento de los hidrogeles de gelatina e hialuronato sódico involucra la formación de enlaces covalentes entre las cadenas de gelatina con las moléculas de genipina, dando lugar a una matriz entrecruzada químicamente que contiene cadenas de hiluronato sódico distribuibs aleto cenas de hialue ariamente, a traves de intracciones tipo Van der Waals (enlaces de hidrogeno, interacciones electrostáticas, fuerzas hidrófobas, etc). Esta matriz da lugar a una red semi-interpenetrada como se muestra en la figura 2a, que es capaz de hincharse aumentando varias veces su peso en seco. Cuando el hidrogel está seco (xerogel) las cadenas poliméricas se encuentran sin estirar. En presencia de agua las cadenas que conforman la red se estiran y el hidrogel se expande hasta alcanzar el hinchamiento en el equilibrio, y éste es el resultado de un balance entre las fuerzas osmóticas que causan que el disolvente penetre entre las cadenas del polímero hidrófilo as fuerzas cohesivas existentes entre estas cadena que oponen resistencia a la expansión (Figura $2 \mathrm{~b}$ ).

A través de la técnica de espectroscopía infrarroja se puede observar el proceso de la reacció de entrecruzamiento (figura 3) a través de la disndas características de los grupos funcionales $\left(\mathrm{vOH}=3600 \mathrm{~cm}^{-1}\right.$ $\left.v \mathrm{NH2}=3400 \mathrm{~cm}^{-1}, \mathrm{vCO}=1660 \mathrm{~cm}^{-1}\right)$ del hidrogel en el espectro ATR-FTIR. Cuando se produce el entrecruzamiento a través de enlaces de hidrógeno entre los grupos $\mathrm{OH}, \mathrm{COOH}$ y $\mathrm{NH} 2$, se observa un ensanchamiento y una disminución en la intensidad de las bandas características. Además al aumentar el tiempo de reacción, se observa la aparición de una segunda señal de un grupo carbonilo $\left(v \mathrm{CO}=1620 \mathrm{~cm}^{-1}\right)$ que se debe al entrecruzamiento químico que se produce entre la gelatima y la genipina que da y la geninin, que da lugar a nuevos enlaces carbonilo con distinto entorno quimico que los originales que presentan los polímeros sin entrecruza $\left(v \mathrm{CO}=1660 \mathrm{~cm}^{-1}\right)$

\section{Grado de Hidratación}

La relación de entrecruzamiento es uno de los factores mas importantes que afectan al hinchamiento de los hidrogeles y se define como la relación entre los moles de agente entrecruzante y los de las unidades de polímero que forman el hidrogel. Cuanto mayor es la cantidad de agente entrecruzante incorporado en la estructura del hidrogel mayor es el entrecruzamiento, dando lugar a hidrogeles con una estructura más compacta, y que se hinchan menos. El grado de hidratación de lo hidrogeles preparados se midió a $37^{\circ} \mathrm{C}$ utilizando medios acuosos a distintos $\mathrm{pH}(2,7.4$ y 10). En la figura 4 se puede observar el perfil de hidratación de los hidrogeles entrecruzados con distintas concentraciones de genipina e hinchados a $\mathrm{pH}=7.4$. En todos los sistemas, el hidrogel mostró un máximo de hidratación y luego disminuye hasta alcanzar un valor estable, que es lo que denominamos el grado de hinchamiento en equilibrio $\left(\mathrm{W}_{\mathrm{e}}\right)$, y este comporamiento se debe a una respuesta viscoelástica del hidrogel. Al principio el sistema se encuentra en estado sólido (xerogel), formando una red rígida. Cuando el sistema empieza a hidratarse las cadenas polimericas se hinchan y adquieren mayor flexibilidad, alcanzando el máximo grado de hidratación. Sin embargo, el sistema tiende con el tiempo a un estado de mínima energía, de forma que las cadenas empiezan a relajarse y contreen, expulsando 


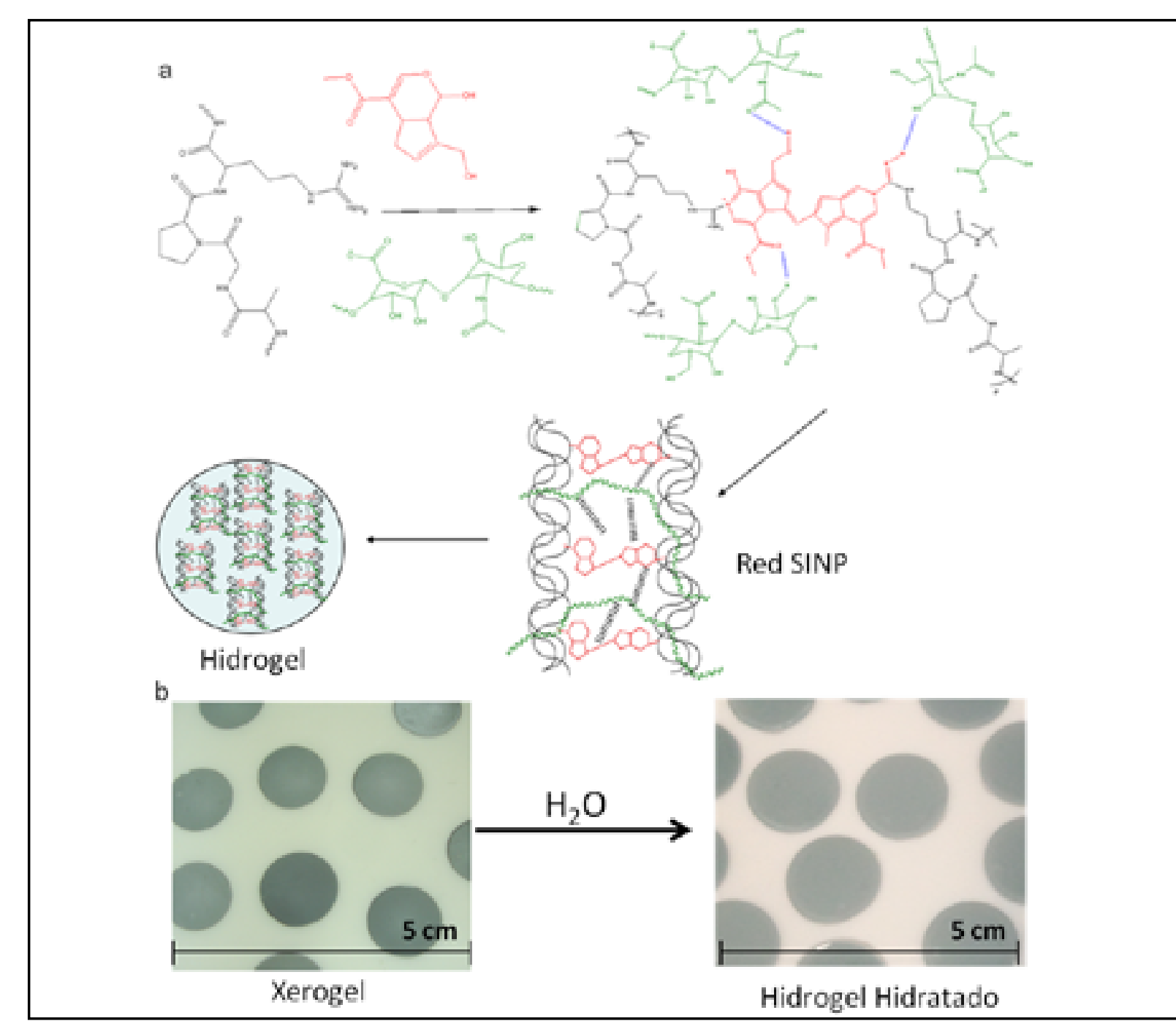

Figura 2. a) Esquema de la formación de la capa de hidrogel compuesta por $60 \%$ en peso de gelatina y $40 \%$ en peso de hialuronato sódico entrecruzado con $1 \%$ en peso genipina, b) Fotografía obtenidas de los xerogeles y los hidrogeles hinchados en agua.

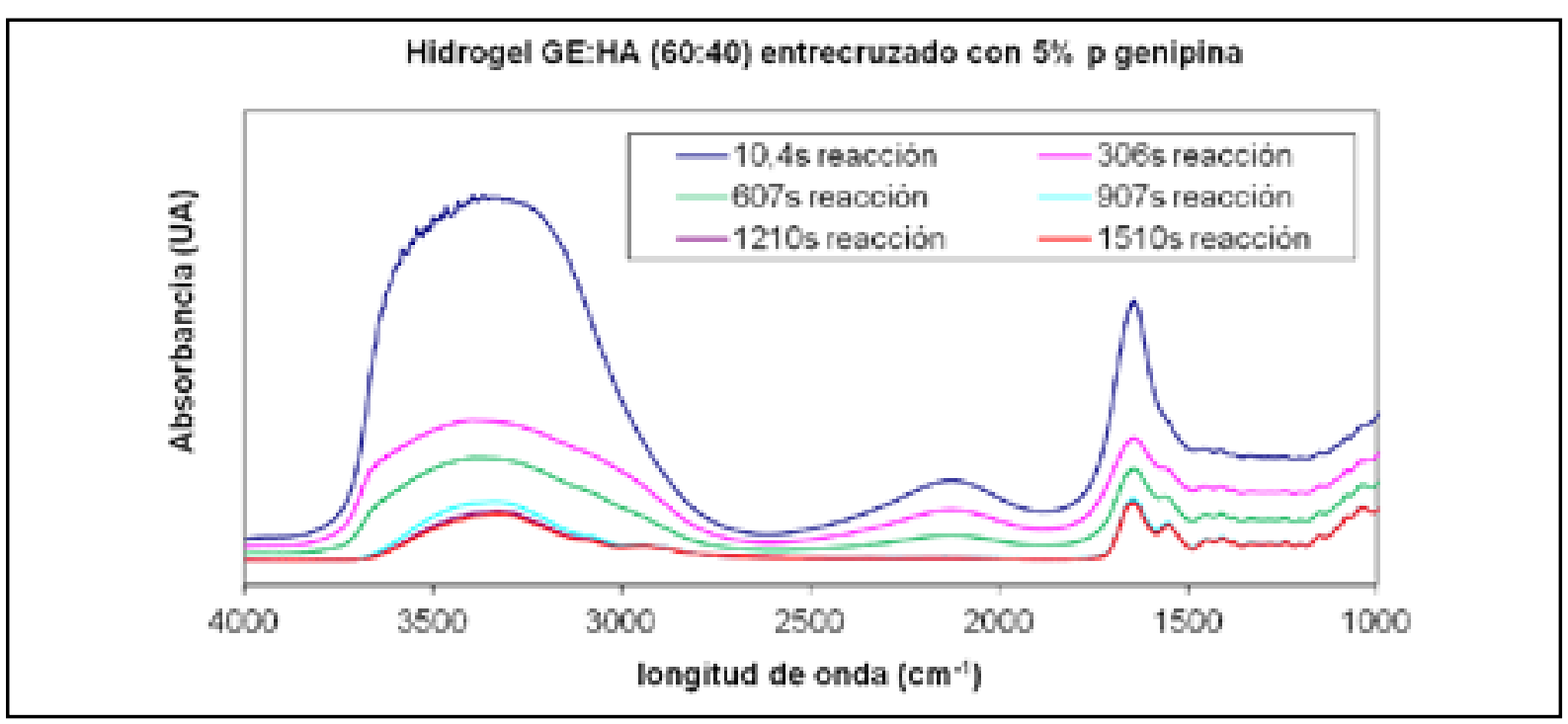

Figura 3. Espectros ATR-FTIR del sistema gelatina-hialuronato sódico entrecruzado con 5\% en peso de genipina a distintos tiempos de reacción. polimérica, hasta alcanzar un grado de hidratación los hidrogeles preparados con un 5\% de entrecruestable. Este efecto es menor cuanto mayor es el zante y 3000\% para aquellos preparados sólo con grado de entrecruzamiento y es característico de los un $0.5 \%$.

hidrogeles viscoelásticos.

El grado de hidratación en el equilibrio alcanEado por cada uno de los hidrogeles entrecruzados con distints concentraciones degenina hin dos a distinos $\mathrm{H}$ se representa en la figra 5. Se observa que conforme aumenta la concentración de agente entrecruzante disminuye el máximo de hidratación alcanzado en el equilibrio. Esto se debe a que el hidrogel presenta un mayor grado de entrecruzamiento, por tanto es más compacto y el disolvente penetra menos en la estructura polimérica. El grado de hidratación en el equilibrio de los geles

Además se observó que a $\mathrm{pH}=7.4$ los hidrogeles presentan un mayor grado de hidratación que $\mathrm{pH}=2$ y $\mathrm{pH}=10$ y además comienzan a degradarse antes. Asi, los hidrogeles entrecruzados con un $1 \%$ de genipina comenzion a degradarse a los $48 \mathrm{~h}$ $\mathrm{pH}=7.4$ ientas que $\mathrm{pH}=2 \mathrm{y} \mathrm{pH}=10$ la degradación del hidrogel comenzó a partir del sexto y séptimo dia respetivamente. Esto se debe a que a $\mathrm{pH}=2$ los grupos and per en la gelatina están protonados $\left(\mathrm{pK}_{\mathrm{a}}=4.8\right)$ y por ello van interaccionar ionicamente con los grupos carbonentrecruzados con genipina varía entre $1200 \%$ para do lugar a interacciones iónicas que proporcionan

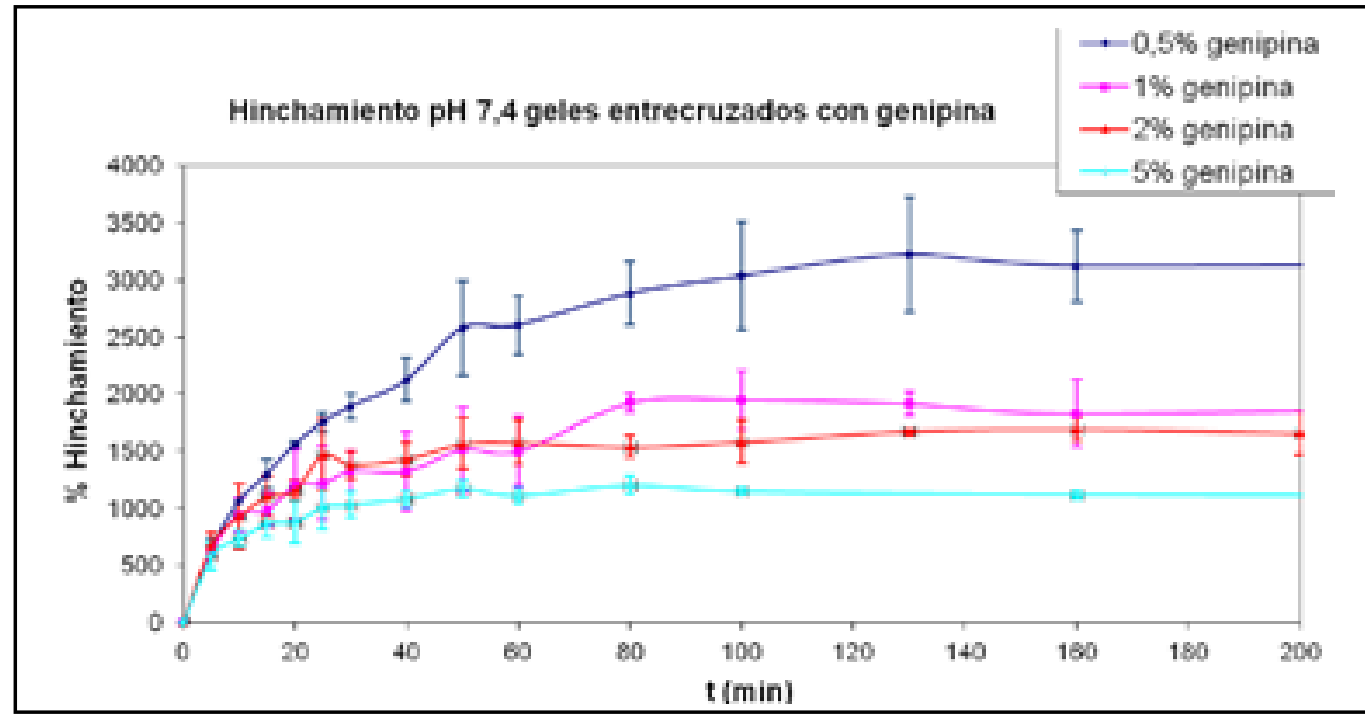

Figura 4. Perfil de hinchamiento de los hidrogeles formados por gelatina: Hialuronato sódico (60:40) entrecruzados con distintas concentraciones de genipina en PBS ( $\mathrm{pH}=7.4)$.

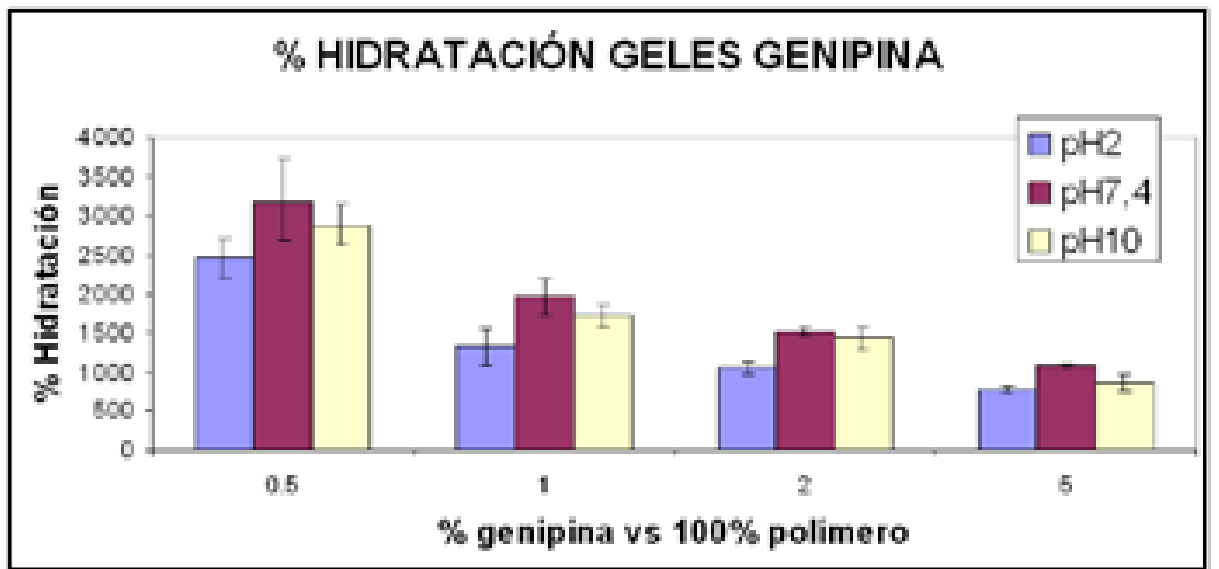

Figura 5. Grado de hidratación alcanzado en el equilibrio de los hidrogeles formados por gelatina:hialuronato sódico $(60: 40)$ entrecruzados con distintas concentraciones de genipina (\%p/p genipina/polímero) e hinchados a distintos $\mathrm{pH}$ 

convierte en un miche

un mayor grado de entrecruzamiento de la estructura del hidrogel. $\mathrm{A} \mathrm{pH}=10$ los grupos carbonilos $\left(\mathrm{pK}_{\mathrm{a}}=9.4\right)$ están cargados negativamente y pueden interaccionar con los grupos amino libres presentes en la estructura. Sin embargo, a pH=7.4 los grupos ionicos están parcialmente cargados y la interacción iónica que existe entre ellos es de menor fuerza, esto permite una mayor penetración de las moléculas de agua en la matriz, lo que conlleva un mayo grado de hidratación y más rápida degradación.

\section{Grado de Entrecruzamiento}

Un hidrogel entrecruzado que se encuentra formando una malla o red tridimensional, puede resistir esfuerzos mucho mayores sin perder su forma original, puesto que los enlaces intermoleculares evitan el desplazamiento de unas cadenas con respecto a otras. Cuando un hidrogel está hinchado se coniste a la tracion y al desge el contenido de agua tiene una gran influencia en las propiedades mecánicas, el comportamiento elástico y la rigidez de los hidrogeles depende de su estructura molecular, de la densidad de entrecruzamiento de la formación de enlaces covalentes y de las fuerzas de interacción iónica, polares y/o estericas. La determinación de estos parámetros se pueden llevar a cabo a partir de los estudios de hinchamiento de los hidrogeles, aplicando la teoría del equilibrio de equilibrio la suma de energías libres es igual a cero: $\frac{1}{M_{c}}=\frac{2}{M_{n}}-\frac{\frac{\bar{v}}{\nu_{1}}\left[\operatorname{hn}\left(1-v_{2,}\right)+v_{2,}+\infty_{2}^{2}\right]}{v_{2,3}^{y_{3}}-\frac{v_{2}}{2}}$

Donde $\mathrm{M}_{\mathrm{n}}$ es el peso molecular promedio en número del polímero lineal $v$ es el volumen especifico del polimero seco, $\mathrm{V}_{1}$ corresponde al volumen molar del disolvente, $v_{2, \mathrm{~s}}$ es la fracción en volumen del polímero en el equilibrio de hinchamiento, y $\chi$ es el parámetro de interacción polímero-disolvente. ${ }^{23}$

A partir de los valores de peso molecular promedio entre nudos $\left(\mathrm{M}_{\mathrm{c}}\right)$ podemos calcular 1 densidad de entrecruzamiento $\left(\rho_{\mathrm{x}}\right)$, que se define como el número promedio de unidades de polímero entre dos nudos consecutivos. Una densida de entrecruzamiento baja permite tener una red más abierta, $\mathrm{y}$ un mayor grado de hinchamiento en cambio, una alta densidad de entrecruzamiento implica un menor grado de hinchamiento y un hidrogel menos deformable.

$$
\rho_{x}=\frac{1}{\bar{v} \cdot \bar{M}_{c}}
$$

Con el objetivo de establecer una comparación entre diferentes valores de $M_{c}$ en función de concentración de entrecruzante, se aplicó el modelo de Flory-Rhener para hidrogeles hinchados en PBS ( $\mathrm{pH}=7.4)$, considerando el volumen molar de agua $V_{1}=18.1(\mathrm{~mL} / \mathrm{mol})$, el peso molecular promedio de la gelatina $\mathrm{M}_{\mathrm{n}}=50000$, la densidad de $\mathrm{la}$ gelatina a $25^{\circ} \mathrm{C}, \rho_{\mathrm{GE}}=1.44 \mathrm{~g} / \mathrm{mL}$ y el parámetro de interacción gelatina-agua tabulado en bibliografia $\chi_{\mathrm{GE}}=0.49 \pm 0.05 .23$ Los resultados obtenidos $\mathrm{de}$ Mc aś como de la densidad de entrecruzamiento (P) se recogen en la tabla 1 Se observa que al almentar la concentración de agente entrecuzante, el peso molectlr promedio entre nuds disminye, es decir la longitud de las cadeas polsminiye, es decir, la longitud de las cadenas poliméricas entre dos puntos de unión es menor, mientras que la densidad de entrecruzamiento aumenta, dando lugar a una matriz más compacta.

\begin{tabular}{|l|l|l|}
\hline HG & $\mathrm{M}_{\mathrm{c}}$ & $\rho_{\mathrm{x}}$ \\
\hline $0,5 \%$ genipina & $408 \pm 48$ & $0.17 \pm 0.02$ \\
\hline $1 \%$ genipina & $224 \pm 15$ & $0.30 \pm 0.02$ \\
\hline $2 \%$ genipina & $166 \pm 31$ & $0.41 \pm 0.08$ \\
\hline $5 \%$ genipina & $103 \pm 10$ & $0.65 \pm 0.06$ \\
\hline
\end{tabular}

Tabla 1 Peso molecular promedio entre nudos y densidad de entrecruzamiento de los hidrogeles de gelatina e hialuronato sódico entrecruzados con distintas concentraciones de genipina.
Estabilidad Mecánica

Los estudios reológicos nos permiten determina y cuantificar las propiedades mecanicas de los HG cuando éstos sufren una deformación determinada. Para determinar las propiedades viscoelásticas de los HG preparados se realizaron ensayos dinamomecánicos de deformación, tiempo y frecurncia

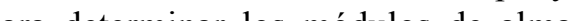
(G") de cada sistema entrecruzado y estimar la transición sol-gel de cada sistema.

Barridos de deformació

Los barridos de deformación se llevaron a cabo para determinar el rango de viscoelasticidad lineal del sistema gelatina: hialuronato sódico (60:40) Este rango se define como el rango en el que el HG cumple la ley de elasticidad de Hooke $(\sigma=$ G $\gamma$, siendo $\sigma$ el esfuerzo aplicado, G el módu$\gamma$ la deformación que sufre el material), y es el rango en el que el sistema pretamiento viscoelástico. El barrido de deformación se realizó entre $1 \cdot 10^{-3}$ y 1000 por ciento de deformación, fijando la frecuencia y temperatura a $0.5 \mathrm{~Hz}$ y $25^{\circ} \mathrm{C}$ respectivamente. E

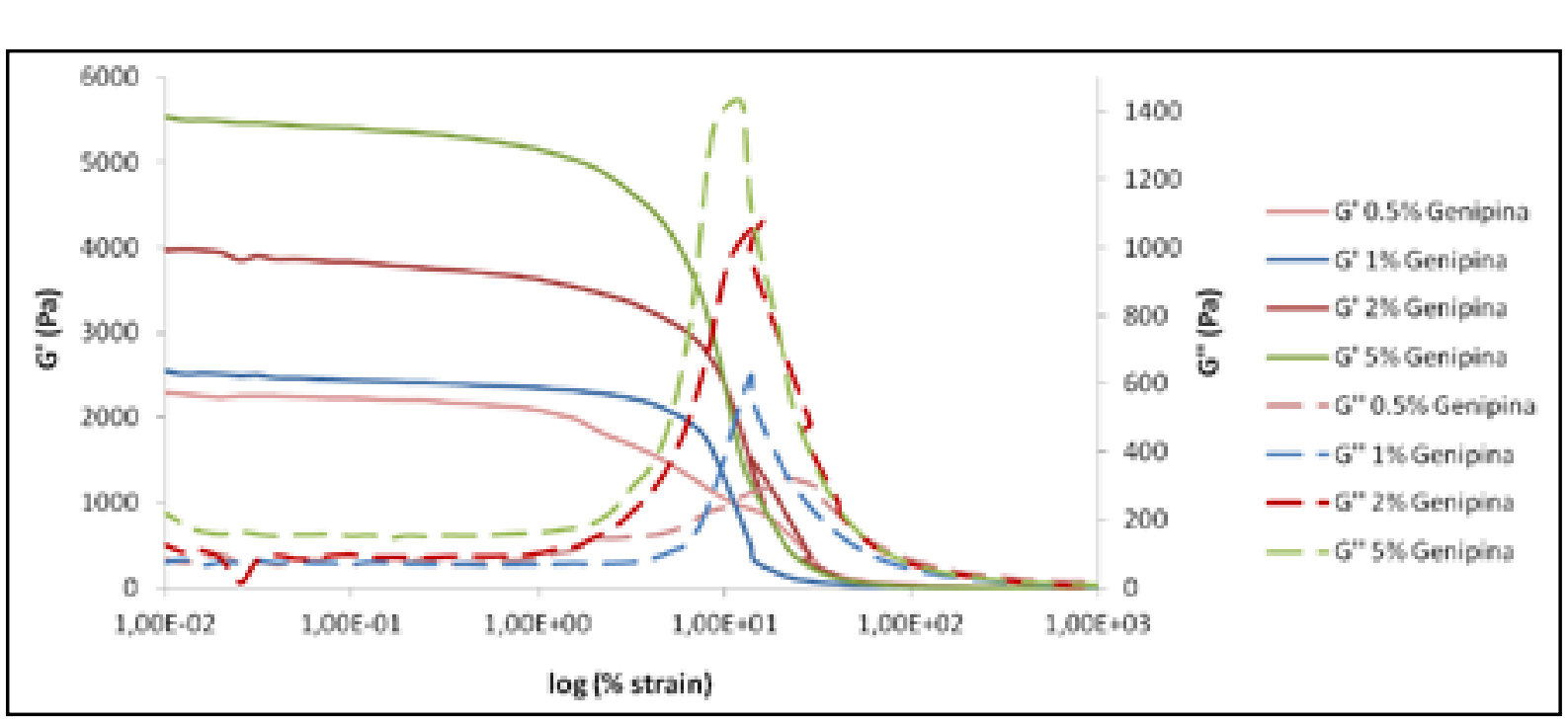

Figura 6. Barrido dinámico de deformación de los HG de gelatina:hialuronato sódico (60:40) enrrecruzados con distintas concentraciones de genipina. En el eje Y de la izquierda se representa valores del módulo de almacenamiento (G'), y en el de la derecha el módulo de pérdidas (G").

\begin{tabular}{|c|c|c|c|c|c|}
\hline & $\begin{array}{c}\text { Gel Control } \\
(0 \% \text { Genipina })\end{array}$ & $\begin{array}{c}\text { Genipina } \\
0.5 \%\end{array}$ & $\begin{array}{c}\text { Genipina } \\
1 \%\end{array}$ & $\begin{array}{c}\text { Genipina } \\
2 \%\end{array}$ & $\begin{array}{c}\text { Genipina } \\
5 \%\end{array}$ \\
\hline $\mathrm{t}(\mathrm{min})$ & $177 \pm 3$ & $106 \pm 5$ & $88 \pm 2$ & $45 \pm 2$ & $39 \pm 1$ \\
\hline
\end{tabular}

Tabla 2. Tiempo medio $\left(25\right.$ y $\left.37^{\circ} \mathrm{C}\right)$ en el que el módulo de almacenamiento (G') corta al módulo de pérdidas (G") en el barrido de tiempo realizado a $2 \%$ de deformación y $0.5 \mathrm{~Hz}$. 
centración. La media de ambos valores se muestra en la tabla 2. Se observa como al aumentar el grado de entrecruzamiento, disminuye el tiempo que arda en producirse la transicion sol-gel.

- Barridos de frecuencia

El barrido de frecuencia se realizó con un $2 \%$ deformación entre 0.01 y $100 \mathrm{~Hz}$ a $25^{\circ} \mathrm{C}$. La estabilización de G' hacia las etapas finales (Figura 8) nos define las propiedades viscoelásticas del gel formado. Se observa como al aumentar la concentración de entrecruzante, el valor del módulo de almacenamiento y el módulo de pérdidas aumenta (Tabla 3), indicándonos una mayor estabilidad del gel. En el gel control (el que no contiene agente en el valor de ambos módulos (G'y G”), indicándonos que esta estructura gel no es estable.

Estabilidad Térmica

Se realizaron análisis termogravimétricos (TGA) de los sistemas entrecruzados con genipi-

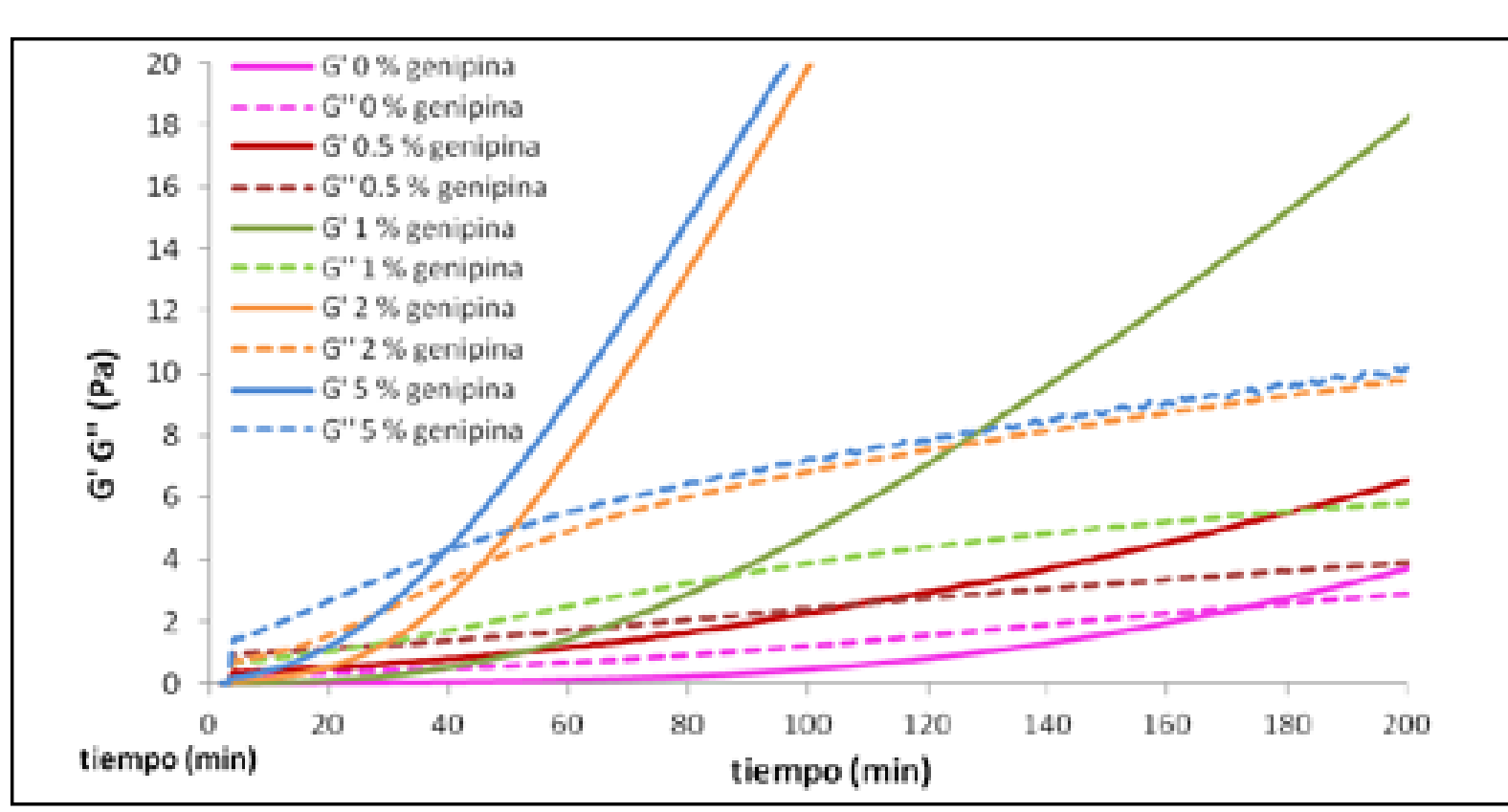

Figura 7. Barrido dinámico de tiempo de los HG de gelatina: hialuronato sódico (60:40) entrecruzados con distintas concentraciones de genipina. El punto donde se cortan ambos módulos (G' y G") se considera el tiempo al que tiene lugar la transición sol-gel.

\begin{tabular}{|c|c|c|c|c|c|}
\cline { 2 - 6 } \multicolumn{1}{c|}{} & $\begin{array}{c}\text { Gel Control } \\
(0 \% \text { Genipina })\end{array}$ & $\begin{array}{c}\text { Genipina } \\
0.5 \%\end{array}$ & $\begin{array}{c}\text { Genipina } \\
1 \%\end{array}$ & $\begin{array}{c}\text { Genipina } \\
2 \%\end{array}$ & $\begin{array}{c}\text { Genipina } \\
5 \%\end{array}$ \\
\hline $\mathrm{G}^{\prime}(\mathrm{Pa})$ & 378 & 1060 & 3740 & 6400 & 20120 \\
\hline $\mathrm{G}^{\prime \prime}(\mathrm{Pa})$ & 61 & 94 & 212 & 385 & 1300 \\
\hline
\end{tabular}

Tabla 3. Valores de los módulos de almacenamiento (G’) y pérdidas (G”) en estado gel.

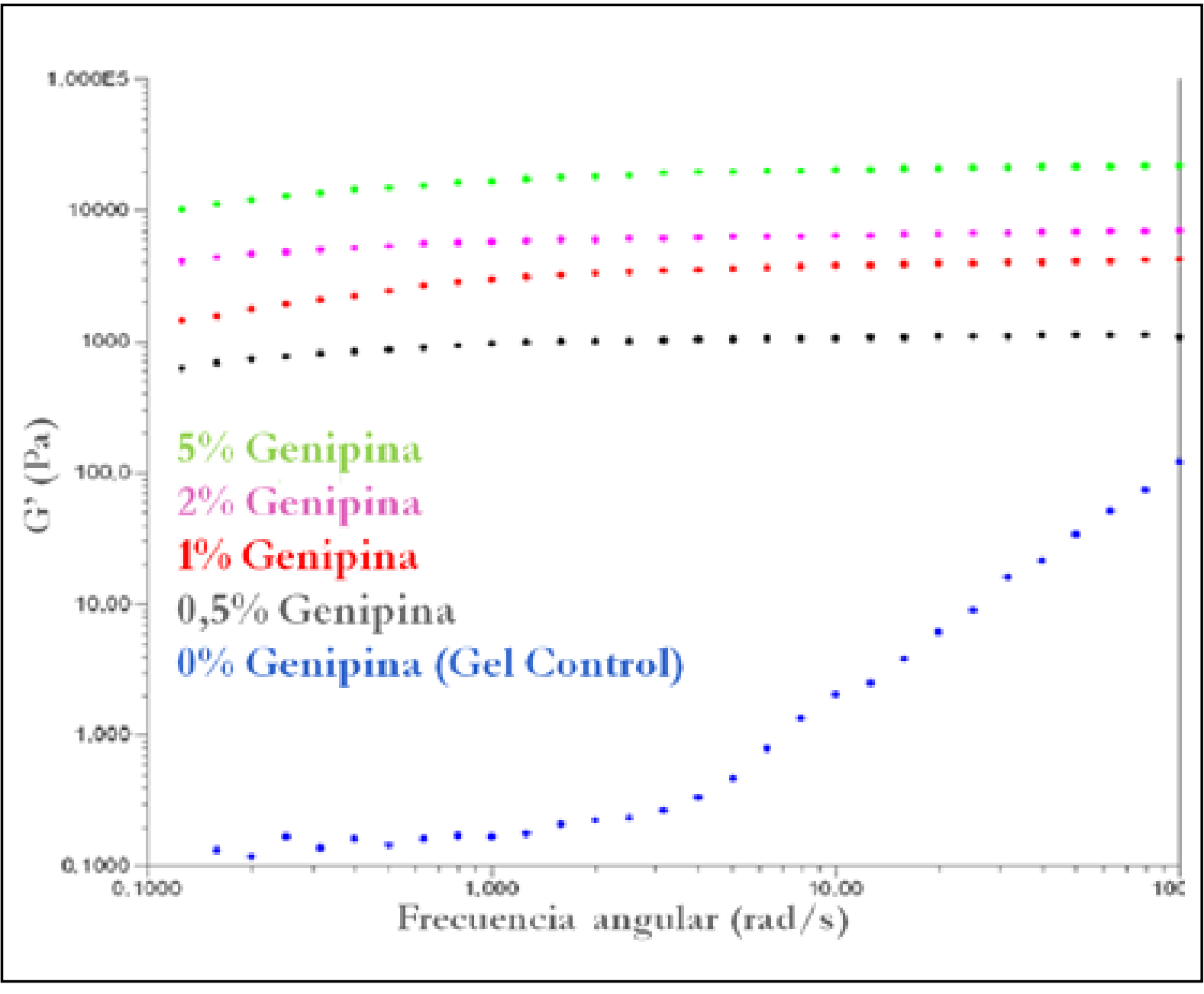

Figura 8. Barridos de frecuencia del sistema gelatina: hialuronato sódico (60:40) utilizando distintas concentraciones de genipina como agente entrecruzante.

\begin{tabular}{|c|c|c|}
\hline MUESTRA & $\mathrm{T}_{10 \%}\left({ }^{\circ} \mathrm{C}\right)^{1}$ & $\mathrm{~T}_{\max }\left({ }^{\circ} \mathrm{C}\right)^{2}$ \\
\hline HG CONTROL & 105 & 312 \\
\hline HG Genipina $0.5 \%$ & 105 & 314 \\
\hline HG Genipina $1 \%$ & 110 & 317 \\
\hline HG Genipina 2\% & 135 & 319 \\
\hline HG Genipina 5\% & 140 & 322 \\
\hline
\end{tabular}

(1) $\mathrm{T}_{10 \%}=$ Temperatura a la que se ha degradado el $10 \%$ del sistema.

(2) $\mathrm{T}_{\mathrm{max}_{\mathrm{x}}}=$ Temperatura a la cual la velocidad de degradación es máxima, según la derivada de la curva del termograma.

Tabla 4. Temperaturas de degradación del sistema gelatina:hialuronato sódico (60:40) entrecruzado con distintas concentraciones de genipina. 


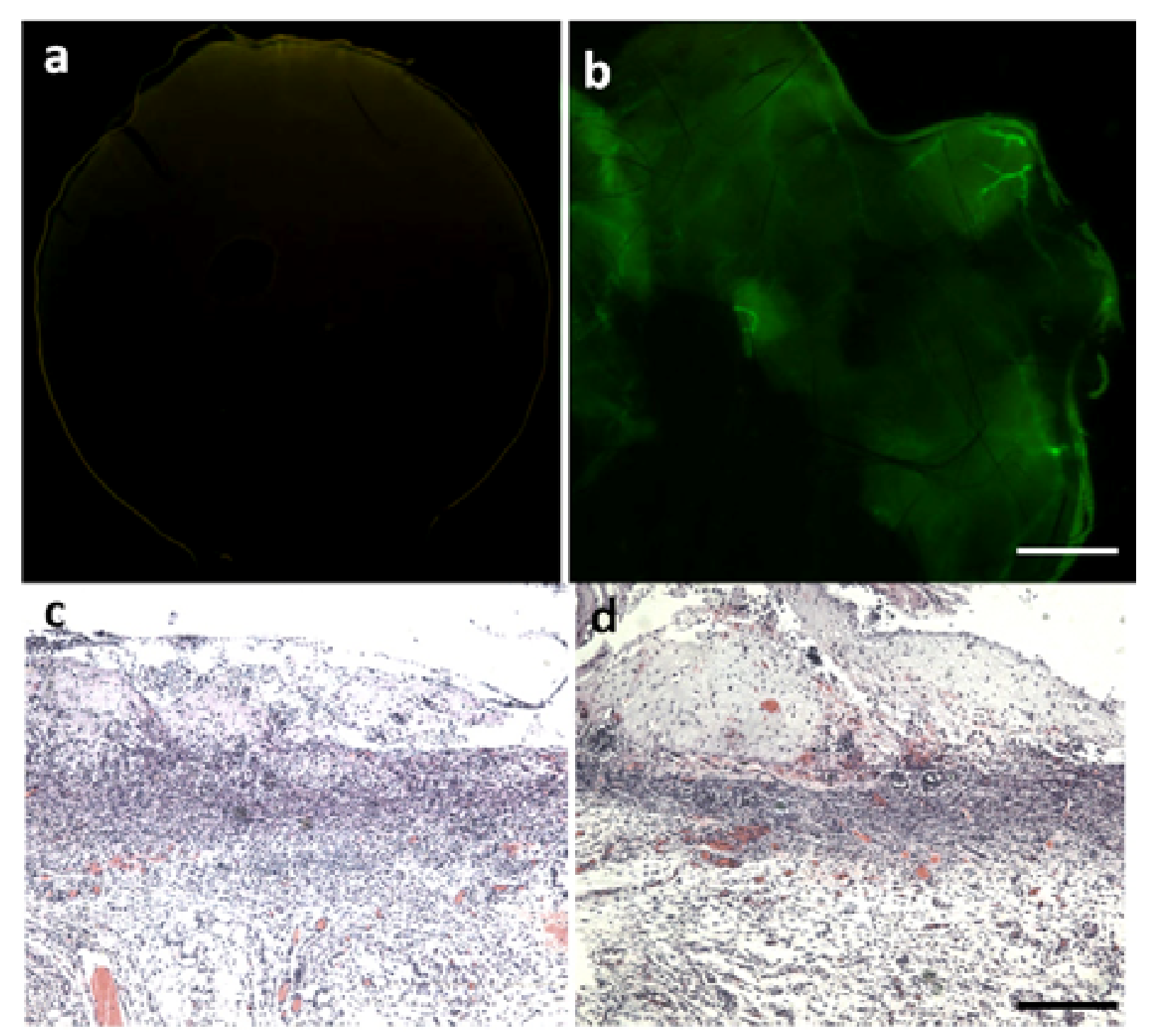

Figura 9. Imágenes obtenidas con el microscopio confocal (a,b) y de campo claro (c,d) de los hidrogeles insertados bajo la piel de los ratones. a) micrografía del hidrogel control (formado por el hidrogel sin PAMP), b) micrografía del hidrogel que contiene $1 \mathrm{nmol}$ PAMP, después de haber sido injertados durante 5 días bajo la piel de los ratones. c) imagen del corte histológico transversal del tejido teñido con hematoxilina-eosina tras 14 días de implantación del sistema control, d) imagen del corte histológico transversal del tejido con sistema que contiene PAMP implantado. Barras de aumento: $\mathrm{a}, \mathrm{b}=75 \mu \mathrm{m} ; \mathrm{c}, \mathrm{d}=150 \mu \mathrm{m}$.

\section{Conclusiones}

Se prepararon redes poliméricas semi-interpenetradas de gelatina e hialuronato sodico entrecruzadas con distintas concentraciones de genipina. La caracterización de estos hidrogeles por reología y los estudios de hinchamiento permitieron determinar su estabilidad mecánica y propiedades viscoelásticas del sistema entrecruzado. Se ha obvervado que la densidad de entrecruzmiento do sistema aumenta con el aumento de concentro de de la genipina, y esto permite modular el grado de hinchamiento alcanzado en el equilibrio. El hin作

\section{Agradecimientos}

Este trabajo se ha realizado gracias a la financiación de los proyectos MAT2010-18155, SAF2009-13240-C02-01 y del CIBER-BBN. Felisa Reyes Ortega agradece la adjudicación de un contrato del CSIC JAE-predoctoral.
1. Hutmacher, D. W.; Sittinger, M.; Risbud, M. v., Scaffold-based tissue engineering: rationale for computer-aided design and solid free-form fabrication systems. Trends in Biotechnology 2004 $22(7), 354-362$.

2. Van Vlierberghe, S.; Dubruel, P.; Schacht, E. Biopolymer-Based Hydrogels As Scaffolds for Tissue Engineering Applications: A Review. Biomacromolecules 2011, $12(\mathrm{~J}), 1387-1408$.

3. Hoare, T. R.; Kohane, D. S., Hydrogels in drug delivery: Progress and challenges. Polymer 2008, 49 (8), 1993-2007.

4. Hennink, W. E.; van Nostrum, C. F., Novel crosslinking methods to design hydrogels. Adanced Drug Delivery Reviews 2002, 54 (1), 1336.

5. Jeong, B.; Kim, S. W.; Bae, Y. H., Thermosensitive sol-gel reversible hydrogels. Advanced Drug Delivery Reviews 2002, 54 (1), 37-5

6. Vanderhooft, J. L.; Alcoutlabi, M.; Magda, J. J.; Prestwich, G. D., Rheological Properties of Cross-Linked Hyaluronan-Gelatin Hydrogels fo Tissue Engineering. Macromolecular Bioscience
2009, 9 (1), 20-28. 2009, 9 (1), 20-28.

Muzzarelit, R. A. A.; Greco, F.; Busilacchi, A. Sollazzo, V.; Gigante, A., Chitosan, hyaluronan and chondroitin sulfate in tissue engineering for cartilage regeneration: A review. Carbohydrate

8. Collins, M.; Birkinshaw, C., Physical propertie of crosslinked hyaluronic acid hydrogels. Jour2008, 19 (11), 3335-3343.

9. Gontiya, G.; Galgali, S., Effect of hyaluronan on periodontitis: A clinical and histological study. 012. Vol. 16, p 184-192.

10. Yoo, H. S; Lee, F A, Y Yoon, J J J Park T. G. folds for cartilage tissue engineering. Biomate-

11. Pal, K.; Banthia, A. K.; Majumdar, D. K., Preparation and characterization of polyvinyl alcool-gelatin hydrogel membranes for biomedica applications. AAPS PharmSciTech 2007, 8 (1)

12. Peng, H. T.; Martineau, L.; Shek, P. N., Hydrogel-elastomer composite biomaterials: 3 . Effect of gelatin molecular weight and type on the preparation and physical properties of interpenetrating polymer networks. Journal of Materials Science Materials in Medicine 2008, 19 (3), 997-1007. Hyaluronic acid modified biodegable

13. Zandi, M.; Mirzadeh, H.; Mayer, C., Effect of concentration, temperature, and $\mathrm{pH}$ on chai mobility of gelatin during the early stages of gelation. Iranian Polymer Journal (English Edition) 2007, 16 (12), 861-870

4. Matsuda, S.; Iwata, H.; Se, N.; Ikada, Y., Bioadhesion of gelatin films crosslinked with glutaraldehyde. Journal of Biomedical Materials

Research 1999, 45 (1), 20-27.

Ai, H.; Mills, D.; Jonathan, A.; Jones, S., Gelatin-glutaraldehyde cross-linking on silicone growth. In Vitro Cell.Dev.Biol.-Animal 2002, 38 (9), 487-492.

16. Gough, J. E.; Scotchford, C. A.; Downes, S Cytotoxicity of glutaraldehyde crosslinked collagen/poly(vinyl alcohol) films is by the mecharials Research 2002, 61 (1), 121-130

17. Wang, C.; Lau, T. T.; Loh, W. L.; Su, K. Wang, D.-A., Cytocompatibility study of a natuCrosslinker-Genipin with thermodel cells. Journal of Biomedical Matejials Research Part B: Applied Biomaterials 2011, 7B (1), 58-65.

18. Bigi, A.; Cojazzi, G.; Panzavolta, S.; Roveri, N.; Rubini, K., Stabilization of gelatin films by crosslinking with genipin. Biomaterials 2002, 23 4827-4832.

19. Nickerson, M. T.; Farnworth, R.; Wagar, E.; Hodge, S. M.; Rousseau, D.; Paulson, A. T. Some physical and microstructural properties of elatin-maltodextrin hydrogels. International Journal of Biological Macromolecules 2006, 38 (1), 40-44

20. Yoo, J. S; Kim, Y. J. Kim, S. H.; Choi, S. H., Study on genipin: A new alternative natura crosslinking agent for fixing heterograft tissue. Korean Journal of Thoracic and Cardiovascula Surgery 2011, 44 (3), 197-207.

21. Eto, T., A review of the biological properties and clinical implications of adrenomedullin and proadrenomedullin N-terminal 20 peptide (PAMP), hypotensive and vasodilating peptides. Peptides 2001, 22 (11), 1693-1711.

22. Martínez, A.; Bengoechea, J. A.; Cuttitta, F Molecular Evolution of Proadrenomedullin NTerminal 20 Peptide (PAMP): Evidence for Gene Co-Option. Endocrinology 2006, 147 (7), 34573461. 